\title{
O PIBID PEDAGOGIA E A APRENDIZAGEM DA DOCÊNCIA: ENTRE PROPOSIÇÕES E AÇÕES EFETIVAS
}

\author{
EL PIBID PEDAGOGÍA Y EL APRENDIZAJE DE LA DOCENCIA: ENTRE \\ PROPOSICIONES Y ACCIONES EFECTIVAS
}

\author{
PIBID PEDAGOGIA AND THE EDUCATION LEARNING: BETWEEN \\ PROPOSITIONS AND EFFECTIVE ACTIONS
}

\author{
Edilaine do Rosário NEVES ${ }^{1}$ \\ Alvanize Valente Fernandes FERENC ${ }^{2}$
}

RESUMO: O objetivo do artigo é analisar o processo de aprendizagem da docência, por parte de estudantes de Pedagogia, ao se inserirem e desenvolverem atividades na escola, por meio do Programa Institucional de Bolsa de Iniciação à Docência (PIBID/2012). Para fins deste artigo, tratamos das ações previstas para as licenciandas, no decorrer da participação no Programa; as implicações; as potencialidades e as limitações dessas ações em seus processos de aprendizagem da docência. Como instrumentos de coleta de dados, foram utilizados o questionário, a entrevista semiestruturada, as observações nas reuniões do PIBID e a visita às escolas em que cinco graduandas atuavam. Os dados da pesquisa nos permitiu constatar que a maioria das ações previstas no Subprojeto do PIBID Pedagogia para as licenciandas, apesar de sofrer alterações, se efetivou na prática; as estudantes vivenciaram a escola de forma exploratória e participativa; fizeram-se presentes em reuniões, oficinas e eventos acadêmico-científicos, favorecendo aprendizagens da docência, algumas propiciadas de forma mais intensa (relativas ao contexto educativo, aos alunos e suas características, ao trabalho em equipe, ao lidar com os imprevistos) e outras menos (planejamento do ensino, domínio do conteúdo, modos de ensinar e relacionamento com os alunos).

PALAVRAS CHAVE: PIBID Pedagogia. Proposições e ações. Aprendizagem da docência.

RESUMEN: El objetivo del artículo es analizar el proceso de aprendizaje de la docencia, por parte de estudiantes de Pedagogía, al insertarse y desarrollar actividades en la escuela, por medio del Programa Institucional de Beca de Iniciación a la Docencia (PIBID/2012). Para este artículo, tratamos de las acciones proyectadas para los estudiantes de un curso de formación docente, en el transcurrir de la participación en el Programa; las implicaciones; las potencialidades y las limitaciones de esas acciones en sus procesos de aprendizaje de la docencia. Como instrumentos de recopilación de datos, fueron utilizados el cuestionario, la entrevista semiestructurada, las observaciones en las reuniones del PIBID y la visita a las escuelas en que cinco estudiantes actuaban. Los datos de la investigación nos permitieron constatar que la

\footnotetext{
${ }^{1}$ Professora na Secretaria de Estado da Educação de Minas Gerais. Mestre em Educação e graduada em Pedagogia pela Universidade Federal de Viçosa. Email: edilaineneves17@ gmail.com

2 Professora do Departamento de Educação da Universidade Federal de Viçosa. Doutora e Mestre em Educação pela Universidade Federal de São Carlos. Email: avalenteferenc@gmail.com
} 
mayoría de las acciones propuestas en el Subproyecto del PIBID Pedagogía para las estudiantes, aunque haya ocurrido modificaciones, se realizó en la práctica; las estudiantes vivenciaron la escuela de forma exploratoria y participativa; se hicieron presentes en reuniones, talleres y eventos académico-científicos, favoreciendo aprendizajes de la docencia, algunas ofrecidas de forma más intensa (relativas al contexto educativo, a los alumnos y sus características, al trabajo en equipo, al lidiar con los imprevistos) y otras menos (planificación de la enseñanza, dominio del contenido, modos de enseñar y relacionamiento con los alumnos).

PALABRAS CLAVE: PIBID Pedagogía. Proposiciones y acciones. Aprendizaje de la docencia.

ABSTRACT: This research was developed having as objective to analyze the process of education learning, by students of Pedagogy when inserting and developing activities at school, through the Institutional Program Initiation of Scholarship to Teaching (PIBID/2012). For purposes of this paper, we treat the actions planned by the students during the participation in the Program; implications; the potential and limitations of these actions in its teaching learning processes. As data collection instruments, we used the questionnaire, the semi-structured interviews, observations of the meetings of PIBID and the visit to schools where five graduation students used to study. The survey data allowed us to find that although they have gone under changes, most of the actions set out in Subproject PIBID Pedagogia for students were effective in practice; the students experienced the school of exploratory and participatory way; They were present at meetings, workshops and academic and scientific events, favoring the teaching learning, some afforded more intensely (on the educational context, students and their characteristics, to teamwork, to deal with the unexpected) and other less (concerning the planning of teaching, content matters, ways of teaching and interaction with students).

KEYWORDS: PIBID Pedagogia. Propositions and actions. Education learning.

\section{Introdução}

Partindo da concepção de que aprender a docência é uma tarefa complexa, processual, que requer diferentes saberes, adquiridos nos mais diversos espaços e momentos da trajetória de vida de quem se propõea aprender a ensinar, como bem sinalizou Mizukami (2004; 2005-2006; 2010) em suas discussões sobre esta temática; considerando, também, que a literatura aponta a iniciação à docência como um período potencializador dessa aprendizagem, (MARCELO, 1997; MIZUKAMI et al., 2010; TARDIF, 2011, MARIANO, 2012), buscamos investigar, analisar e compreender o processo de aprendizagem da docência de licenciandas em Pedagogia de uma Instituição Pública de Ensino, situada na Zona da Mata mineira, ao inserir e desenvolver 
atividades na escola, por meio do Programa Institucional de Bolsa de Iniciação à Docência - PIBID 2012.

Nessa pesquisa, empregamos como instrumento de coleta de dados questionário contendo questões fechadas, entrevista semiestruturada, observações nas reuniões do PIBID e visita às escolas em que as licenciandas atuavam, visando obter, por meio da perspectiva de cinco licenciandas ${ }^{4}$ integrantes do PIBID Pedagogia (edital de 2012), informações sobre os aspectos relativos às expectativas de aprendizagem no PIBID; às ações que desenvolvem no decorrer da participação no Programa; às relações que estabelecem no interior da escola; às contribuições e limitações do PIBID para a construção da aprendizagem da docência; bem como o que pensam sobre a escola e o aprender a ensinar.

Para este artigo fizemos um recorte na pesquisa e exploramos as proposições do Subprojeto do PIBID Pedagogia, as ações que as licenciandas desenvolvem no decorrer da participação no Programa e as implicações, potencialidades e limitações dessas ações em seus processos de aprendizagem da docência. Entendemos que as ações previstas, quando efetivadas, podem favorecer a construção dessa aprendizagem, bem como compreendemos que o "clima escolar" (COSTA, 2008) infere no trabalho das licenciandas e nos seus processos de socialização na profissão.

As duas escolas nas quais essas estudantes atuavam, ambas municipais de ensino fundamental, receberam nomes fictícios: Escola Girassol e Escola Cactos. A primeira apresenta uma relação de maior interação, proximidade, respeito e união entre seus membros e entre esses e as integrantes do PIBID; na segunda há uma relação entre profissionais e licenciandas que se caracteriza pelo distanciamento.

Com respeito à aprendizagem da docência, é pertinente considerar que apesar de ter sido evidenciada quando do diálogo sobre o PIBID, ela é decorrente também de outros espaços e momentos da trajetória de vida desses sujeitos, como nos fazem pensar

${ }^{3}$ O PIBID, iniciado em 2007, é um Programa de incentivo e valorização do magistério e de aperfeiçoamento do processo de formação de docentes para a educação básica. Concede bolsa de iniciação à docência a alunos de cursos de licenciatura que exerçam atividades pedagógicas em escolas públicas de educação básica e aos responsáveis pela coordenação (professores da universidade) e supervisão (professores da escola de educação básica) destas atividades (BRASIL, 2012).

${ }^{4} \mathrm{O}$ número total de licenciadas bolsistas do PIBID Pedagogia, edital de 2012, são vinte. Para a pesquisa selecionamos sete que se encontravam no nível intermediário do curso e possuíam mais de um ano de participação no Programa. Destas sete, cinco aceitaram o convite para participar da pesquisa. Estas são do sexo feminino, suas idades variam de 21 a 23 anos, têm um tempo de 1 ano e 5 meses a 1 ano e 7 meses de atuação no PIBID. 
as discussões de Mizukami et al. (2010) e Tardif (2011), dentre outros, ao afirmarem que o aprender a ser professor é processual e proveniente de vários contextos sociais.

O interesse por realizar estudos sobre o PIBID Pedagogia está atrelado, entre outros aspectos, ao fato de uma das autoras deste artigo ter sido bolsista desse Programa e ter percebido suas implicações em seu próprio processo formativo e, também, à crescente ampliação dos Projetos PIBID em âmbito nacional. Sobre este último aspecto, cabe destacar que este projeto se configura atualmente como o segundo maior Programa de Bolsas da Capes e possui perspectivas de consolidação e continuidade na agenda das políticas públicas educacionais (BRASIL, 2012).

Em face dessas considerações, discorreremos sobre o PIBID Pedagogia apresentando seu objetivo e suas proposições; em seguida abordaremos as ações que se efetivam na prática, bem como as implicações dessas ações para a construção da aprendizagem da docência das licenciandas bolsistas do Programa.

\section{O PIBID Pedagogia: entre proposições e ações efetivas}

Incorporado à universidade pesquisada desde 2009, o PIBID Pedagogia estudado representa para o licenciando uma oportunidade de compreender a complexidade da escola ao experienciá-la de forma a traçar, conforme definição contida nos documentos da instituição, novas configurações teóricas e metodológicas. Durante o tempo de participação no Programa, o estudante é acompanhado por professores, tanto da graduação quanto da educação básica.

No PIBID Pedagogia, as ações previstas estão organizadas em quatro blocos temáticos: I) conhecer a escola; II) conhecer a sala de aula e o trabalho docente; III) vivenciar a dinâmica da sala de aula; IV) pesquisar e intervir, sempre que possível, no processo de aprendizagem.

Uma leitura geral das informações contidas nos blocos temáticos nos permitiu identificar, como proposições aos bolsistas de iniciação à docência, a inserção no espaço escolar e, nesse âmbito, o conhecimento de sua realidade "de forma exploratória e participativa", tendo contato com os documentos oficiais da escola (calendário, regimento escolar e Projeto Político Pedagógico - PPP); conhecer os atores nela envolvidos - alunos, professores, diretores, pais de alunos e demais funcionários; familiarizar-se com a sala de aula e o trabalho docente. 
Ainda de acordo com os documentos da instituição, as licenciandas que atuam no PIBID podem, nesse processo, acompanhar crianças com dificuldades de aprendizagem; participar das reuniões com os pais de alunos buscando colaborar no atendimento a eles; realizar avaliações referentes ao Ensino e Aprendizagem da leitura e escrita; identificar os desafios que os alunos enfrentam no ensino da linguagem; colaborar na construção de uma Proposta Pedagógica para a alfabetização inicial; elaborar e ministrar aulas; participar dos momentos de estudos coletivos e do planejamento docente; trabalhar com os professores de forma exploratória e participativa; colaborar nas reuniões pedagógicas e na elaboração e correção das avaliações; favorecer a alfabetização; elaborar e ministrar aula, sob a orientação do professor e do supervisor; pesquisar casos de crianças com dificuldades, planejar e intervir utilizando-se de metodologias diferenciadas, a fim de ajudá-las a superarem suas dificuldades; produzir e divulgar conhecimentos advindos da experiência no PIBID.

Frente à descrição acima, sobre o PIBID, podemos dizer que experiências propiciadoras da vivência de distintas dimensões do trabalho docente ao longo do curso de graduação são apontadas como necessárias à formação de professores, por favorecerem a construção da aprendizagem da docência (PIMENTA, 2007; CARVALHO; UTUARI, 2007; MIZUKAMI, et al., 2010; TARDIF, 2011). Entre os elementos potencializadores da construção dessa aprendizagem, Mizukami et al. (2010) e Tardif (2011) ressaltam o exercício da profissão e a relação com outros, em especial com os pares e os alunos.

Nesse sentido, temos como pressuposto, conforme evidenciado na introdução, que as proposições presentes no subprojeto em questão, quando efetivadas, possam propiciar a aprendizagem da docência. Assim, consideramos relevante compreender quais ações se efetivam na prática.

Percorrendo os dados da pesquisa identificamos que as integrantes do Programa empreendem as seguintes ações:

a) no âmbito escolar: realizam leitura dos documentos oficiais da instituição; observam as aulas ministradas por uma professora da escola; participam de festas/cerimônias; auxiliam a professora e os alunos em sala de aula, nos momentos em que a professora desenvolve atividades; realizam atividades com os alunos, tanto em grupo quanto individualmente; participam das reuniões ocorridas com os pais dos alunos, com as professoras e com a supervisora do PIBID. 
b) na universidade: participam de reuniões com a coordenadora do PIBID Pedagogia, das oficinas de formação por ela oferecidas, dos eventos englobando todos os PIBIDs da instituição; elaboram relatórios; ministram oficinas temáticas; participam e/ou divulgam conhecimentos produzidos com base nas experiências no PIBID em eventos ligados ao ensino, à pesquisa e à extensão, tanto na universidade em que cursam Pedagogia, quanto em outras instituições.

Vimos então, que a maioria das ações previstas têm sido empreendidas no âmbito do Programa. Entretanto, identificamos divergências na sua implementação, ou seja, algumas são realizadas de forma distinta ao que foi proposto, outras desenvolvidas apenas por um grupo de licenciandas, além de implementadas de forma diversa por elas.

A existência de modificações no processo é uma questão apontada como recorrente no desenrolar da implementação de políticas, entre elas, as educacionais (RUS PEREZ, 2010; EVANGELISTA, 2008). Entre os aspectos que concorrem para isso, Rus Perez (2010) elenca: a questão temporal, contextual, organizacional e as características e o comportamento dos envolvidos. E analisa, ainda, que "esse conjunto de fatores, interagindo entre si e com a estratégia de implementação, pode afetar o grau de alcance dos resultados e formas de implementação" (RUS PEREZ, 2010, p. 1190). A dimensão temporal, contextual e pessoal influiu também na implementação do PIBID Pedagogia.

Na pesquisa que desenvolvemos as aulas que as licenciandas deveriam ministrar e a participação nas reuniões da escola foram atividades que apresentaram discrepância com aquelas propostas no Programa. Essas aulas deveriam ser supervisionadas pela professora e pela supervisora do PIBID Pedagogia, mas nem sempre o foram. Isso foi colocado pelas licenciadas de ambas as escolas. Elas ainda evidenciaram casos em que a professora raramente esteve presente. Quanto à presença da supervisora, nestes momentos, os dados produzidos sinalizam sua ausência, visto sequer ter sido mencionada pelas licenciandas.

Quanto às reuniões do PIBID Pedagogia na escola vimos que além de não serem realizadas de forma colaborativa conforme previsto, raramente foram concretizadas pelas estudantes vinculadas à Escola Cactos. As estudantes que se encontravam inseridas na Escola Girassol, na maioria das vezes, realizaram essa atividade. Isso se deveu ao fato de haver, nesta escola, uma relação de maior proximidade, respeito e união entre seus membros e entre estes e as integrantes do Programa, reforçando, assim, a ideia da interferência do clima escolar no trabalho das licenciandas e nos seus 
processos de aprendizagem da cultura de uma instituição, das regras e dos valores da profissão.

Quanto às atividades realizadas pelas licenciandas de forma distinta daquela proposta pelo Programa, a observação das aulas ministradas por uma professora da escola se caracteriza como um exemplo disso. Apesar de todas as licenciandas desenvolverem esta ação, a forma como o fazem, por meio de observação e/ou de observação participante diverge de uma para a outra. Há aquelas que ficam apenas observando, passivamente, nos momentos em que a professora desenvolve atividades, e há as que realizam intervenções no intuito de auxiliar os alunos e a professora. Isso indicará que as orientações recebidas dão margem à diversificação ou é a prática pedagógica que favorece o imprevisto e o diverso? Pensamos que a relação com a professora regente encaminha de modo distinto, as maneiras de estar no contexto da aula.

Outra ação realizada pelas integrantes do Programa, diferentemente do que fora proposto, são as atividades junto aos alunos. Algumas priorizam desenvolver esta ação apenas em sala de aula; outras as implementam também de forma individual, com aqueles alunos que apresentam dificuldades de aprendizagem e indisciplina. Entre as que optaram por não trabalhar individualmente com as crianças, encontramos justificativas de que temiam estigmatizá-las e que tinham interesse em desenvolver atividades condizentes com o papel que precisarão assumir como professora, além da crença de que é mais adequado para os alunos trabalhar dessa forma. Nesse aspecto também se mostra em aberto a conduta no contexto escolar. Quem determina que os estudantes merecem atenção individual ou não? O que essa ação efetivamente colabora para as aprendizagens dos estudantes?

Foi possível perceber, a partir dos dados da pesquisa, que as demandas colocadas pelos profissionais da escola, segundo informação de uma das colaboradoras desta pesquisa, são sutis e não explícitas. Dessa forma, as licenciandas acabam fazendo atividades além das exigidas pelo PIBID Pedagogia, por vezes sendo inibidas de fazer o que almejam. Realizam atividades de suporte operacional, evidenciadas no regulamento do Programa (CAPES, 2013) como vedadas às bolsistas de iniciações à docência. Há momentos em que são inibidas de trabalhar com atividades de cunho lúdico e artístico, o que atenderia à demanda do Subprojeto de experienciar metodologias diferenciadas, por exemplo. Há uma dimensão relacional (professor regente $\mathrm{X}$ licenciandas), que diz respeito também à autoridade pedagógica que atravessa as ações no contexto de sala de 
aula, determinando o que se pode e o que não se pode fazer. Nessa perspectiva, o que originalmente fora planejado sofre intervenções do contexto escolar e das relações que aí se estabelecem.

Ainda, a prática de produzir e divulgar os conhecimentos construídos por meio da experiência no PIBID, prevista no Subprojeto, também não é muito recorrente. Apesar de haver estímulo financeiro ${ }^{5}$ e uma cobrança da coordenadora neste sentido, as licenciadas deixaram transparecer que carecem de mais orientação para que consigam elaborar seus trabalhos e publicá-los. Há aqui também uma relação de exterioridade das estudantes com as ações que lhes cabe desenvolver. Parece-nos que elas estão constantemente a depender de outros, seus supervisores, seus professores, para que consigam efetivar o que lhes é proposto.

Constatamos, no entanto, que mesmo as ações propostas sofrendo alterações ao serem efetivadas, elas propiciam às licenciandas diversas aprendizagens relacionadas ao exercício da docência. Isso quer dizer que as mudanças de rumo precisam ser pensadas quanto à sua efetividade no processo de formação de professores e não simplesmente no que tange ao processo de definição de novos rumos, em si.

\section{Aprendizagens da docência reveladas por estudantes bolsistas do PIBID Pedagogia}

Apesar do desencontro entre propostas e ações, conforme foi exposto acima, as ações desempenhadas pelas licenciandas favoreceram diversas aprendizagens da docência. Algumas foram proporcionadas de forma mais intensa e outras menos. As mais intensas foram relativas ao contexto educativo, aos alunos e suas características, ao exercício da reflexão, ao trabalho em equipe e ao saber lidar com os imprevistos. Já as menos intensas foram referentes à pesquisa sobre o ensino, ao domínio da língua escrita, ao planejamento do ensino, ao domínio do conteúdo, ao modo de ensinar, ao relacionamento com os alunos e à avaliação da aprendizagem. Esses saberes, em sua maioria, são sinalizados também na literatura e considerados imprescindíveis aos professores para que possam ensinar e conduzir as aprendizagens dos alunos (SHULMAN, 1986; GARCIA, 1999; NONO, 2001; TARDIF; RAYMOND, 2000; ZEICHNER, 2008; TARDIF, 2011; por exemplo).

${ }^{5}$ De acordo com o artigo 24 da portaria $\mathrm{n}^{\circ}$ 096, de 18 de julho de 2013, esse estímulo financeiro para publicação e apresentação de trabalhos, palestras, minicursos, oficinas e correlatos relacionados ao PIBID, ocorre mediante custeio com locomoção, diárias e alimentação. Sendo que esse valor pode atingir no máximo $40 \%$ do montante de recurso aprovado para o Projeto. 
Focando as aprendizagens proporcionadas de forma mais intensa, podemos destacar, mais especificamente, àquelas que dizem respeito ao contex to educativo e aos alunos e suas características, à aquisição de conhecimentos sobre normas de funcionamento da escola, à organização dos tempos e espaços, às condições físicas e materiais da escola e características cognitivas e socioculturais dos alunos. Essas, conforme Garcia (1999), são aprendizagens comumente adquiridas em contato com os alunos e com as escolas reais.

Cabe destacar a prática reflexiva, apontada na literatura como importante para que professores e futuros professores possam compreender, avaliar e questionar suas próprias crenças e práticas institucionais (PÉREZ GOMEZ, 1995; TARDIF, 2011; MIZUKAMI et al., 2010; GARCIA, 1999; dentre outros). Foi possível perceber que houve um "reflexivo mais prático que teórico", ou seja, restrito às questões vivenciadas no âmbito escolar, relativos às práticas observadas ${ }^{6} \mathrm{e}$ realizadas; uma reflexão relacionada às ações e reações dos alunos, às atividades que deram "certo" ou não e seus porquês, às estratégias a serem usadas para obter melhorias, mas desvinculadas de uma fundamentação teórica e problematizadora sobre o assunto.

O desenvolvimento de um exercício reflexivo, mas que englobe também a perspectiva teórica e problematizadora é defendido por autores como Zeichner (2008). O autor sinaliza “[...] que a 'reflexão' por si mesma significa muito pouco” (p. 545) e ainda afirma: "as pesquisas recentes mostram a importância de se estruturar e de se apoiar as reflexões dos licenciandos, por meio de atividades reflexivas, em vez de apenas dizer aos estudantes para saírem por aí refletindo sem o mínimo de instrução para isso" (p. 546-547).

Dessa forma, uma sistematização das reflexões desenvolvidas no âmbito do PIBID mostra-se pertinente, posto que esse Programa propõe aos futuros professores uma iniciação à docência orientada e supervisionada. Nessa perspectiva, é interessante que haja em seu interior estratégias capazes de estimular e orientar as estudantes a desenvolverem reflexões mais profundas, densas e problematizadoras sobre o que elas têm observado, realizado e aprendido no processo. Essa orientação pode ocorrer, por exemplo, quanto ao aprimoramento e à criação de táticas capazes de mobilizar as

${ }^{6}$ Estamos nos referindo aqui às práticas das professoras das Escolas Cactos e Girassol com os seus alunos em sala de aula, que as licenciandas observaram. Reflexões sobre tais práticas, mais especificamente sobre conteúdos escolhidos pelas professoras, o modo como ensinavam os alunos, os avaliava e se relacionavam com eles, por exemplo, foram socializadas, especialmente nas reuniões do Programa. 
licenciandas a pensar sobre a seleção dos conteúdos, os materiais e métodos de ensino; sobre o ensino em si e os propósitos dele; sobre a influência do contexto em suas práticas, as implicações de suas ações e do currículo escolar na aprendizagem dos alunos e delas próprias, tanto em termos cognitivos quanto éticos, políticos e sociais.

Outro aspecto que ficou evidente no âmbito do PIBID foi a pouca ocorrência do trabalho em equipe, principalmente entre as licenciandas inseridas na escola Cactos. De maneira geral, cada licencianda desenvolve atividades com a turma que acompanha. Contudo, foi possível observar indícios de práticas colaborativas, com socialização de conhecimentos e experiências entre as licenciandas que integram o Programa, assim como entre essas e algumas professoras da escola, mais especificamente as docentes responsáveis pelas turmas nas quais as licenciandas estão inseridas. Nessas interações há, por exemplo, socialização dos conteúdos das atividades que realizam, dos instrumentos e meios que utilizam para desenvolvê-los, das implicações das atividades desenvolvidas na aprendizagem dos alunos e nas reações e sentimentos das licenciandas, bem como dos aspectos relativos às características e desempenho dos alunos e as formas de relacionamento com eles.

O estabelecimento de relações de "partilha" e apoio entre as próprias licenciandas e entre essas e algumas professoras da escola, nos parece acenar para o "rompimento da cultura individualista do ensino e a construção de culturas de colaboração verdadeiras dentro das escolas” (NUNES, 2001, p. 580). Essa cultura é propiciadora de aprendizagens da docência nos seguintes aspectos: no trato dos conteúdos, relacionamento com os alunos, nas formas de lidar com os sentimentos pessoais e imprevistos, etc.

Com relação ao aprendizado no saber lidar com os imprevistos, foi ressaltada sua ocorrência, principalmente quando da realização de atividades junto aos alunos no contexto escolar. Nesses momentos, frequentemente, elas tinham que improvisar, pensar em soluções frente a situações concretas, buscar, por exemplo, alternativas e recursos diferentes dos planejados, adequar as atividades à estrutura da escola e ao comportamento dos alunos. Isso denota que elas estavam aprendendo um aspecto, considerado na literatura (IMBERNÓN, 2006; MIZUKAMI, et al., 2010; TARDIF, 2011, dentre outros) como característico do exercício do trabalho docente junto aos alunos, que diz respeito à dinamicidade, à imprevisibilidade e à imediatez das decisões e tarefas conduzidas em seu âmbito. 
Discutindo agora sobre as aprendizagens viabilizadas de forma menos intensa, podemos localizar a carência de pesquisa sobre o ensino. Temos depoimentos que ressaltam a pouca recorrência de práticas de produzir e divulgar os conhecimentos construídos a partir da experiência no PIBID. Isso pode ser atribuído à pouca iniciativa das licenciandas em realizar esta ação e também à sua carência de maiores orientações quanto à elaboração e publicação de seus trabalhos.

De acordo com Nono (2001), uma das competências linguísticas necessárias ao ensino da leitura e da escrita é o domínio da língua escrita. Os dados da pesquisa apontam que essa competência necessita ser mais bem aprimorada, tendo em vista as ressalvas feitas pelas licenciandas sinalizando a necessidade de mais orientação nesse sentido.

Outra prática que as estudantes apontaram que necessitavam de maior orientação diz respeito ao planejamento de aulas. Disseram, na maioria dos casos, que não sabiam fazer essa atividade. Abordaram dificuldades e angústias sentidas nesse processo, enfatizando principalmente a dificuldade em planejar aulas que contemplassem distintos alunos e a angústia frente a aulas ocorridas de forma distinta ao que fora planejado. Explicitadas como recorrentes no desenvolvimento do ensino (MARIANO, 2012), essas dificuldades e angústias indicam a necessidade de uma melhor organização no planejamento de aulas e uma reflexão sobre as possíveis alterações que podem ocorrem quanto à sua implementação.

O aprendizado do conteúdo específico, considerado por Shulman (1986) como um elemento essencial à base do conhecimento docente, também foi abordado pelas licenciandas como um dos saberes pouco proporcionados no âmbito do PIBID. O domínio desse conhecimento, segundo Shulman (1986), é imprescindível para o desenvolvimento de um ensino de qualidade. Sem delegar essa função exclusivamente aos cursos de formação docente (até porque consideram ser a formação docente uma ação contínua), a literatura destaca a necessidade de esses cursos não negligenciarem tal conhecimento. Isso é válido também no contexto do PIBID, pois, como nos alertam alguns autores, o escasso domínio do conhecimento específico pode acarretar consequências à aprendizagem dos alunos, favorecer o planejamento de aulas baseadas em informações equivocadas; desconsiderar conteúdos relevantes (NONO, 2001); limitar as intervenções dos estudantes (GARCIA, 1999), dentre outras coisas.

Para além de dominar o conteúdo, dominar o modo como ensiná-lo também é imprescindível para que o professor possa promover o aprendizado dos alunos. No 
contexto da pesquisa, esse conhecimento, bem como aquele relativo ao planejamento do processo de ensino-aprendizagem, foi indicado como sendo propiciado de forma pontual, esporádica e pouco sistematizada, ora por meio de uma oficina apenas, ora nos momentos em que as licenciandas realizavam observações e intervenções na escola, por exemplo.

A questão acima, juntamente com o fato de o domínio do modo de ensinar os conteúdos constituírem "um verdadeiro desafio pedagógico" (TARDIF, 2011, p. 120) parece justificar a existência de depoimentos em que se revela a insegurança a como fazer a transposição didática. Abordando essa insegurança, uma das participantes da pesquisa assim se expressou:

Eu ainda fico muito perdida, assim... em relação ao que eu devo fazer, como fazer, principalmente, o como fazer. Eu sei que... eu posso até saber o que o aluno naquela idade teria que aprender, e tal. Mas, muitas vezes, eu não consigo fazer essa transposição didática. É uma coisa bem complicada assim.

Essa insegurança pode ser compreendida, visto o domínio dos modos de ensinar ser complexo; demandar, conforme mostra Garcia (1999), saber quais são os propósitos de ensinar determinados conteúdos e a sua sequência adequada; saber escolher, criticar, adaptar e utilizar os materiais e recursos disponíveis; conhecer e utilizar estratégias e métodos de ensino (metáforas, explicações, ilustrações, por exemplo) que tornem o conteúdo compreensível e interessante para os alunos e que promovam suas aprendizagens.

Sobre o conhecimento relativo à avaliação da aprendizagem dos alunos, apesar de as licenciandas evidenciarem sua "aquisição" mediante o relacionamento com os alunos e a professora, sinalizaram, por outro lado, não terem aprendido a elaborar avaliações, nem mesmo interpretá-las, visto, dentre outras coisas, não haver, no âmbito do Programa, ações destinadas especificamente a esse fim. Em seus relatos houveram explicitações do tipo:

É uma questão que existe, essa exigência: que a gente tem que fazer um diagnóstico, tem que avaliar. Mas quando faz, muitas vezes, fica sem saber o que fazer com o diagnóstico. Fiz lá a prova, fiz o diagnóstico, mas e aí?! O quê que eu faço com isso? O quê que isso me diz?

Esse depoimento fornece indícios de que, além da prática de avaliar a aprendizagem dos alunos não ser recorrente no âmbito do Programa, não existe uma 
orientação no sentido de favorecer a aprendizagem sobre a formulação de diferentes tipos de avaliações, adequadas à matéria a ser ensinada, aos alunos da classe e, muito menos, quanto à prática de interpretá-las. Na verdade, foi constatado um anseio geral por adquirir esse aprendizado, como se pode visualizar no depoimento a seguir:

Eu acho que seria importante para a gente, pois como futura professora, eu vou ter que saber e já tendo oportunidade, de construir uma, durante a minha formação, quando eu chegar a ser professora seria melhor para mim.

Quanto à avaliação das aprendizagens dos alunos, é de se estranhar que a maioria dessas estudantes não faça menção às aprendizagens ocorridas em outros espaços formativos, como o curso de licenciatura. Esse seria um lugar, também, de aprendizagens sobre práticas avaliativas. Parece-nos haver uma setorização de aprendizagens quando se está no Programa, ou seja, as estudantes pouco mobilizam saberes apreendidos em outros contextos. Ou será que esses saberes não têm se constituído? Isso coloca uma questão maior com respeito à relação entre Cursos de Licenciatura e Programa de Iniciação à Docência. Uma perspectiva é de se trabalhar por meio de casos de ensino ${ }^{7}$, o que quer dizer que a prática de iniciação à docência seria um lugar em que os estudantes organizariam as demandas de formação e que pudessem voltar aos cursos de formação como problema à busca de alternativas e problematizações. Essas situações-problema também poderiam ser trabalhadas junto aos diferentes sujeitos envolvidos no PIBID: professores das escolas, supervisores e orientadores de estágio.

Quanto ao relacionamento com os alunos, as licenciandas revelaram inúmeras aprendizagens, propiciadas ao observá-los e desenvolverem atividades com eles, como, por exemplo: suas características cognitivas, socioculturais, suas ações e reações no decorrer do desenvolvimento do ensino. Todavia, essas estudantes destacaram almejar que houvesse, por parte do Programa, orientações que lhes favorecessem formas de relacionamento capazes de amenizar a indisciplina em sala de aula, conquistar a atenção dos alunos e promover suas aprendizagens a respeito dos conteúdos trabalhados, entre outras questões.

É bastante interessante a localização de demandas de saberes da formação pelas licenciandas. Construir o problema a partir da inserção na realidade educativa é um

7 Os Casos de Ensino podem representar importante estratégia ou instrumento formativo àqueles profissionais que se encontram no exercício da docência. Eles podem servir à reflexão e redimensionamento da prática pedagógica de educadores (MIZUKAMI; NONO, 2002). 
importante passo no processo formativo. Contudo, há que se ressaltar a exterioridade das ações de resolução dos problemas, ou seja, as licenciandas revelam, nos depoimentos, estarem constantemente na dependência de alguém que as oriente, que as conduza. Onde está a perspectiva reflexiva e investigativa frente à prática docente? Percebe-se uma urgência quanto à sistematização dos problemas e à busca de alternativas frente a eles.

O manejo de classe apontado como favorável à promoção das aprendizagens dos alunos (SHULMAN, 1986; GARCIA, 1999 e TARDIF, 2011) é um aspecto que ficou sinalizado como merecedor de orientações capazes de provocar, nas futuras professoras, reflexões sobre o modo como estão lidando com essa dimensão em sala, suas repercussões no comportamento e aprendizagem dos alunos, entre outras questões. Isso pode ser compreendido e reforçado se pensarmos que é com os alunos que as futuras professoras, “ [...] vão solidificando seu eu profissional” ao observá-los, interagir e testar com eles "estratégias de ação pedagógica para uso posterior", conforme argumento de Nunes (2001, p. 721). Esse argumento é igualmente destacado por Lüdke (1996) ao explicitar que “o professor vai 'aprendendo fazendo, com seus alunos' e retendo o que dá certo, incorporando-o para futuras soluções" (LÜDKE, 1996, p. 12). Isso demanda uma ação mais efetiva das licenciandas, uma postura mais instigadora e profissional no contexto escolar. Parece-nos que há um fazer que carece de um saber, de sua problematização. Por fim, cabe salientar que muitas das aprendizagens evidenciadas na pesquisa não se encontram acabadas, mas em processo, e são destacadas na literatura como importantes para que os professores possam ensinar e conduzir as aprendizagens dos alunos. Nesse sentido, consideramos pertinente atentar para as questões expostas pelas licenciandas quanto às potencialidades e limitações do Programa no processo de construção de suas aprendizagens da docência. Essas questões sinalizam a necessidade de repensar a organização de algumas ações no Programa, de modo a conduzir melhor a formação das licenciandas que o integram. Há, portanto, um desafio quanto ao posicionamento dos diferentes sujeitos envolvidos no PIBID: a adoção de uma perspectiva investigativa, problematizadora da realidade e constituidora de um saberfazer.

\section{Algumas considerações}


Buscamos, com este artigo, mapear tanto as ações previstas para as licenciandas integrantes do PIBID Pedagogia 2012, quanto aquelas que vêm sendo efetivadas na prática, bem como as implicações, potencialidades e limitações dessas ações em seus processos de aprendizagem da docência. Com isso, esperamos fomentar discussões no âmbito desse Programa focando as aprendizagens que ele propicia ou que poderia vir a propiciar com maior intensidade.

Sobre as ações previstas no Subprojeto do PIBID Pedagogia às licenciandas, identificamos que a maioria dessas ações se efetiva na prática. As estudantes participaram de reuniões e oficinas do Programa e de eventos acadêmico-científicos. Elas se inseriram no contexto escolar de forma exploratória e participativa, por meio de atividades de observação, planejamento, desenvolvimento de aulas, avaliações dos alunos e participação nas reuniões da escola.

Contudo, algumas dessas ações sofreram alterações quando de sua implementação. Dentre essas atividades podemos destacar as relativas às aulas que as licenciandas deveriam ministrar e a participação nas reuniões da escola.

As aulas ministradas pelas graduandas deveriam ser supervisionadas pela professora regente e pela supervisora do PIBID, mas nem sempre o foram. A este respeito há que se problematizar: quais fatores impedem que esse supervisionamento ocorra? No caso da supervisora é de se estranhar sua ausência, posto estar diretamente envolvida com o Programa, inclusive recebendo bolsa para supervisionar as bolsistas de iniciação à docência. Quanto à ausência das professoras, pensamos que talvez possa estar ligada à sobrecarga de trabalho, problemas familiares e pessoais e até mesmo à sua condição de trabalho, sob contrato temporário. Contudo, é pertinente destacar que em função da ausência dessa profissional, a professora eventual é quem deveria ficar responsável pela turma e não as licenciandas, como ocorrido em algumas situações.

Quanto às reuniões realizadas na escola, vimos que, além de não acontecerem de forma colaborativa, como previsto, raramente foram concretizadas pelas estudantes vinculadas à Escola Cactos. As estudantes que se encontravam inseridas na Escola Girassol, na maioria das vezes, concretizaram tal atividade. Isso se deveu ao fato de haver nessa escola uma relação de maior proximidade, respeito e união entre seus membros e entre esses e as integrantes do Programa.

Esses desencontros entre proposições e ações denotam que o contexto das escolas e as interações constituídas no PIBID, em especial, no interior de cada instituição escolar, encaminham distintamente a conduta das graduandas no Programa, 
diversificando o que fora planejado. Apesar disso, as ações desempenhadas pelas licenciandas favoreceram diversas aprendizagens da docência. Algumas dessas aprendizagens foram propiciadas de forma mais intensa e outras menos.

Conforme foi abordado, as aprendizagens propiciadas de forma mais intensa foram aquelas relativas ao contexto educativo, aos alunos e suas características, ao exercício da reflexão (numa perspectiva mais prática que teórica, segundo as licenciandas), ao trabalho em equipe, ao saber lidar com os imprevistos. Já as aprendizagens viabilizadas de forma menos intensa foram as concernentes à pesquisa sobre o ensino, ao domínio da língua escrita, ao planejamento do ensino, ao domínio do conteúdo, ao modo de ensinar, ao relacionamento com os alunos e à avaliação da sua aprendizagem.

Como um passo na melhoria da aquisição dessas aprendizagens pelas bolsistas de iniciação à docência, os dados da pesquisa indicam a necessidade de uma postura mais engajada, autônoma e profissional dessas graduandas frente às tarefas que lhes são propostas. Isso, considerando que o aprendizado da docência não é algo a ser adquirido passivamente, mas que requer implicação do sujeito em seu processo formativo.

Defender um maior envolvimento das licenciandas em seu processo formativo não implica reduzir o papel da supervisora e da coordenadora nesse processo de aprendizado da docência, posto que elas são também responsáveis por encaminhar essa formação, são até remuneradas para desempenhar esta função. Nesse sentido, carecem de oferecer orientações mais sistemáticas e organizadas acerca das ações planejadas, a serem desempenhadas e observadas pelas graduandas.

Portanto, cabe considerar que a adoção de uma atitude mais ativa por parte dos distintos atores envolvidos com o PIBID precisa favorecer uma perspectiva investigativa, problematizadora das experiências vivenciadas e constituidora de um saber-fazer, conforme foi ressaltado ao longo deste artigo.

Ao apontar as ações previstas às licenciandas bolsistas do PIBID e as ações que se efetivam na prática, trazendo suas repercussões no processo formativo dessas estudantes em termos das aprendizagens que propiciam e do modo como propiciam, os resultados desta pesquisa fornecem dados que indicam o Programa como um avanço importante na qualidade dos cursos de formação de docentes para a educação básica. Contudo, esses dados fornecem igualmente informações para pensar esse Programa: a sua organização, as ações por ele propostas e o modo como estas ações vêm sendo implementadas, as aprendizagens que tem favorecido e/ou poderiam favorecer às 
bolsistas, entre outras contribuições, além de lacunas que se constituem como desafios a serem aprimorados, uma vez que esse Programa é relativamente novo e, portanto, seus rumos ainda estão sendo traçados.

\section{REFERÊNCIAS}

BRASIL. Diretoria de Educação Básica Presencial: relatório de gestão 2009-2011. Brasília, 2012. Disponível em: <http://www.capes.gov.br/images/stories/download/bolsas/DEB_Pibid_Relatorio2009_2011.pdf>. Acesso em: 15 fev. 2013.

CAMPOS, A. B. F. Aprendendo a ser professor: caminhos da formação no início da carreira docente em Geografia. 2013.142 p. Dissertação (Mestrado). Faculdade de Educação, Universidade Federal de Minas Gerais, Belo Horizonte, 2013.

CAPES. Portaria n⿳0 096, de 18 de julho de 2013. Aprova o Regulamento do Programa Institucional de Bolsa de Iniciação à Docência (PIBID). Disponível em: <http://www.capes.gov.br/images/stories/download/legislacao/Portaria_096_18jul13_A provaRegulamentoPIBID.pdf $>$. Acesso em: 12 fev. 2015.

CARVALHO, T. R. D.; UTUARI, S. dos Santos, (Orgs.). Formação de professores e estágios supervisionados: algumas veredas. São Paulo: Andross, 2007.

COSTA, M.Prestígio e hierarquia escolar: estudo de caso sobre diferenças entre escolas em uma rede municipal.Revista Brasileira de Educação,Rio de Janeiro, v. 13 n. 39, p. 455-594, set./dez. 2008. Disponível em:

<http://www.scielo.br/pdf/rbedu/v13n39/04.pdf> Acesso em: 20 fev.2014.

EVANGELISTA, Olinda. Apontamentos para o trabalho com documentos de política educacional. Caros Amigos, ano XII, n. 136, jul. 2008, manchete. Disponível em: <http://www.dfe.uem.br/texto.Olinda.PDF> Acesso em: 07 mai. 2014.

GARCIA, C. M. Formação de professores: para uma mudança educativa. Portugal: Porto Editora, 1999.

IMBERNÓN, F. Formação docente e profissional: formar-se para a mudança e a incerteza. 6ª ed. São Paulo: Cortez, 2006. (Coleção Questões da Nossa Época; v.77)

LÜDKE, M. Sobre a socialização profissional de professores. Cadernos de Pesquisa, São Paulo, n. 99, p. 5-15, nov. 1996.

MARCELO, C. Pesquisa sobre formação de professores: o conhecimento sobre aprender a ensinar. Revista Brasileira de Educação,Rio de Janeiro, n. 9, p. 51-75, Set/Out/Nov/Dez, 1997. 
MARIANO, A. L. S. A aprendizagem da docência no início da carreira:qual política? Quais problemas? Revista Exitus, Santarém, v. 02, nº 01, p.79-94, Jan./Jun. 2012.

MIZUKAMI, M da G. N; NONO, M. A. Casos de ensino e processos de aprendizagem profissional docente. Revista Brasileira de Estudos Pedagógicos, Brasília, v. 83, n. 203/204/205, p.72-84, jan./dez. 2002.

\section{Como referenciar este artigo}

NEVES, Edilaine do Rosário; FERENC, Alvanize Valente Fernandes. O PIBID pedagogia e a aprendizagem da docência: entre proposições e ações efetivas. Revista Ibero-Americana de Estudos em Educação, Araraquara, v. 11, n. 4, p. 2046-2063, 2016. Disponível em: 〈http://dx.doi.org/10.21723/riaee.v11.n4.7816>. E-ISSN: 19825587.

Submetido em: junho/2015

Aprovação final em: novembro/2016 